\title{
Análise do comportamento de concreto com adição de cinza de biomassa vegetal submetido ao ataque de íons sulfato
}

\author{
Analysis of concrete behavior with addition \\ of vegetable biomass ash subjected to the \\ attack of sulfate ions
}

\footnotetext{
${ }^{1}$ Instituto Federal da Paraíba - IFPB, Rua José Antônio da Silva, 300, Jardim Oásis, Cajazeiras, PB, Brasil. e-mail: alicevitoriasb@outlook.com, leonardodiaspb@gmail.com, hebertonlinhares@gmail.com, robson.santos@ifpb.edu.br
}

\section{RESUMO}

Os impactos negativos causados pela construção civil ao meio ambiente são motivados principalmente pela demanda de recursos naturais. A indústria do cimento se destaca por ser responsável por cerca de $5 \%$ das emissões mundiais de $\mathrm{CO}_{2}$. Estratégias vêm sendo utilizadas para reduzir essas emissões, como o aumento no desempenho do ligante a partir da redução do teor deste na produção de concreto, através de métodos de dosagem com o empacotamento de partículas. Nesse sentido, o objetivo do estudo consistiu em avaliar o comportamento do concreto com baixo teor de cimento, e adição de Cinza de Biomassa Vegetal (CBV), exposto a sulfato de sódio. Foi realizado um estudo experimental caracterizando os materiais envolvidos, uma avaliação das alterações dimensionais de corpos de provas de argamassa e análise da fissuração das peças, testes físicos e mecânicos em concreto, submetidos a dois processos de cura (solução de sulfato de sódio ou em cura convencional). O traço foi desenvolvido com o auxílio do software de empacotamento EMMA e planilha presente na literatura, onde reduziu-se o teor de cimento em 10, 15 e 20\% em massa, substituindo por CBV. O material de referência apresentou significativa redução na expansão ao ser exposto à solução de sulfato quando comparado às amostras submetidas à cura convencional. Quanto às misturas acrescidas de CBV, essas apresentaram uma redução de resistência para cura convencional e melhor comportamento quando expostas ao meio agressivo de sulfato, tanto em resistência como em expansão para os traços de 10 e $15 \%$ de redução do cimento, sendo esta última considerada eficiente para meios agressivos.

Palavras-chave: Empacotamento. Cinza de biomassa vegetal. Sulfato de sódio.

\begin{abstract}
The negative impacts caused by civil construction to the environment are motivated mainly by the demand for natural resources. The cement industry stands out for being responsible for about $5 \%$ of global $\mathrm{CO}_{2}$ emissions. Strategies have been used to reduce these emissions, such as increasing the performance of the binder by reducing its content in the production of concrete, through dosing methods with the particle packing. In this sense, the objective of the study was to evaluate the behavior of low-cement concrete, and addition of Plant Biomass Ash (PBA), exposed to sodium sulfate. An experimental study was carried out characterizing the materials used, an evaluation of the dimensional changes of mortar specimens and analysis of the cracking of the pieces, physical and mechanical tests on concrete submitted to two curing processes (sodium sulfate solution or conventional curing). The mix was developed with the aid of the EMMA packaging software and spreadsheet available in the literature, in which the cement content was reduced by 10,15 and $20 \%$ by weight, replacing with PBA. The reference material showed a significant reduction in expansion when exposed to sulfate solution compared to samples submitted to conventional curing. As for mixtures added with
\end{abstract}


PBA, they showed a reduction in strength when exposed for conventional curing and better behavior when exposed to the aggressive sulfate medium, both in strength and in expansion for the mixes with 10 and $15 \%$ cement reduction, the latter being considered efficient for aggressive environments.

Keywords: Packing. Plant biomass ash. Sodium sulphate.

\section{INTRODUÇÃO}

O concreto dentro da sua composição atual passou historicamente por diversas transformações, desde alterações nos seus processos de produção, como também em seus constituintes. Essas modificações, associadas aos avanços tecnológicos e sociais, levaram a mistura a ser o produto mais utilizado dentro da construção civil e o segundo material mais consumido pela humanidade, principalmente pela sua facilidade de produção, sendo fabricadas no mundo anualmente cerca de 25 bilhões de toneladas de concreto, o que corresponde a aproximadamente 3,25 toneladas por pessoa $[1,2]$.

Dentre os materiais que compõem o concreto, o cimento é considerado um elemento nobre para a mistura, formado basicamente pela combinação do clínquer com o sulfato de cálcio e adições, sendo as mais utilizadas o fíler calcário, pozolanas e a escória. Ele é responsável por estabelecer as propriedades ligantes no concreto, proporcionando rigidez e garantindo o bom desempenho no que diz respeito a resistência mecânica, além de ainda influenciar nas características reológicas da matriz [3].

No Brasil, segundo o Sindicato Nacional da Indústria do Cimento-SNIC [4], o consumo aparente no ano de 2018 ultrapassou a margem de 35 milhões de toneladas, deixando-o na posição de $5^{\circ}$ maior consumidor de cimento do mundo. Tendo em vista esse consumo elevado e em consequência, a necessidade constante de intensa produção de cimento, atrelado ao crescimento da construção civil, é notória a importância que a indústria cimenteira apresenta na economia mundial e consequentemente no Brasil.

No entanto, em contrapartida aos avanços proporcionados pelo setor da construção, bem como ao desenvolvimento econômico, vinculado direta ou indiretamente à indústria do cimento, têm-se os impactos ambientais causados na produção deste, principalmente no que se refere aos gases poluentes emitidos em quantidades excessivas na atmosfera, como o dióxido de enxofre $\left(\mathrm{SO}_{2}\right)$ e o dióxido de carbono $\left(\mathrm{CO}_{2}\right)[5,6,7]$.

À medida que a demanda global pelo uso de concreto em aplicações de construção aumenta progressivamente, a indústria da construção civil se depara com o desafio crucial de encontrar estratégias econômicas para reduzir as emissões de $\mathrm{CO}_{2}$ e a energia incorporada associadas à produção de cimento Portland [8, 9].

Segundo Worrell et al. [10], as emissões de dióxido de carbono na fabricação do cimento acontecem em dois momentos, devido à intensa energia utilizada na queima de combustíveis fósseis e pela calcinação da rocha calcária para a produção do clínquer nos fornos rotativos em temperaturas de até $1450^{\circ} \mathrm{C}$. Sendo esse último responsável pela maior emissão de $\mathrm{CO}_{2}$ na indústria do cimento, onde grande parte do produto gerado corresponde a dióxido de carbono, encontrando na literatura valores de 440, 520 até $547 \mathrm{~kg} \mathrm{CO}_{2} / \mathrm{t}$ de clínquer, logo para cada $1000 \mathrm{~kg}$ de carbonato de cálcio $\left(\mathrm{CaCO}_{3}\right)$ calcinado, no mínimo, $440 \mathrm{~kg}$ são de dióxido de carbono [8].

As implicações ambientais causadas pela fabricação do cimento vêm se tornando uma grande preocupação nas indústrias e no meio acadêmico, no que se refere às exigências sociais e governamentais [11]. De modo a encontrar medidas que mitiguem esses impactos, alguns estudos vêm sendo desenvolvidos, como é o caso de KULOVANÁ et al. [12] e ZAHO et al. [13], que avaliaram substituição do cimento Portland por resíduo de tijolo cerâmico, verificando sua atividade pozolânica e melhorias no desempenho dos concretos em relação à durabilidade. Tem-se também a pesquisa realizada por [14] avaliando a produção de concretos auto adensáveis com baixa quantidade de cimento observando a influência dessa consumo na resistência a compressão do concreto

O aumento da eficiência no uso dos ligantes é uma alternativa que pode ser alcançada através de soluções relacionadas às características dos agregados (granulometria, forma, composição), métodos de dosagem, desenvolvimento de clínqueres com maior reatividade, novos ligantes, adições minerais resultantes de resíduos [15]. Como exemplos de alternativas nesse sentido podem ser citados os trabalhos de KAPELKO [16], que apresenta resultados do incremento da eficiência do ligante através de dispersantes e de Damineli, PILEGGI e JOHN [17], que pesquisaram uma alternativa para reduzir o consumo de cimento através do empacotamento da mistura e da dispersão de partículas.

A utilização de adições minerais em substituição ao cimento demanda estudos que contemplem além dos aspectos de resistência mecânica, mas que ressaltem também a influência destas adições na durabilidade do concreto. Os fenômenos físico-químicos causadores de danos nas estruturas de concreto possuem inúmeras origens, se relacionam e reforçam mutuamente, tornando-se difícil separar causa e efeito. Os íons sulfatos 
oriundos do meio, por exemplo, reagem com a portlandita formando subprodutos de caráter agressivo para matriz cimentícia[18, 19].

Não é difícil encontrar consideráveis concentrações de sulfato, pois é comum na maioria dos solos a presença do íon na forma de gipsita $\left(\mathrm{CaSO}_{4} \cdot 2 \mathrm{H}_{2} \mathrm{O}\right)$, em águas usadas em torres de resfriamento ou subterrâneas, poços de mineração e pântanos [20].

Esse íon é considerado um dos agentes mais agressivos de deterioração do concreto. Os meios mais conhecidos do seu ataque são: (1) reação com os produtos de hidratação do cimento formando a etringita e (2) reação com o hidróxido de cálcio, tendo como produto o gesso. De acordo com o íon cátion que estiver ligado ao radical $\mathrm{SO}_{4}{ }^{2-}$, a intensidade do ataque pode variar, trazendo por ordem crescente de agressividade o sulfato de cálcio, seguido pelo de sódio e magnésio, terminando com o sulfato de amônia [21, 22, 23].

Segundo HOPPE FILHO et al [18], duas fases são observadas na degradação do concreto pelo ataque do sulfato, inicialmente ocorre um período de dormência caracterizado pela ação do material expansivo formado preenchendo os poros da estrutura não sendo possível observar alterações significantes e a segunda fase corresponde a uma considerável expansão, trazendo mudanças microestruturais, que traria como consequências perdas de resistência e fissuração.

Os componentes do cimento Portland, produtos da hidratação, que contêm alumina ou hidróxido de cálcio são os mais vulneráveis aos íons sulfato, estes ao entrarem em contato se transformam na forma altamente sulfatada (etringita, $\mathrm{C}_{3} \mathrm{~A} \cdot 3 \mathrm{C} \bar{S} \cdot \mathrm{H}_{32}$ ). Sabendo que a formação da etringita ocorre naturalmente como um processo da hidratação do cimento, ela vem a acarretar problemas quando é formada tardiamente pelo ataque dos sulfatos dos agregados, das fases minerais do clínquer que contêm $\mathrm{SO}_{3}$, ou de forma externa pelos íons encontrados no meio como já mencionado $[24,25,26]$. As reações químicas de trocas de cátions também podem ter como produto a gipsita (sulfato de cálcio hidratado). Esta agride o concreto reduzindo seu $\mathrm{pH} \mathrm{e}$ causando perda de rigidez e resistência, seguidas consequentemente de expansões e fissurações [20].

É possível observar que além da formação da gipsita, a reação do sulfato de sódio com o hidróxido de cálcio tem como produto o hidróxido de sódio, que consegue assegurar a alta alcalinidade do conjunto, mantendo a estabilidade do CSH (produto de hidratação). Embora essa estabilidade seja mantida, as consequências do ataque desse íon podem tomar grandes proporções, sendo assim a qualidade do concreto surge como a principal defesa, principalmente quando se trata da baixa permeabilidade $[20,26]$. Como a reação dos íons sulfatos ocorrem inicialmente com o aluminato de cálcio presente no cimento, Mehta e MONTEIRO [20] trazem que cimentos com teores menores que $5 \%$ de $\mathrm{C}_{3} \mathrm{~A}$ são suficientemente resistentes a sulfato.

Embora existam diversas pesquisas voltadas a analisar a redução do consumo de cimento na produção do concreto, muitas têm o seu foco direcionado a efeitos físicos e mecânicos, fazendo-se necessário uma avaliação mais ampla do comportamento do concreto, de forma a possibilitar sua inserção no mercado. Nesse sentido, o presente estudo surge pela necessidade de avaliar o comportamento quanto aos efeitos físicos e mecânicos que esse tipo de concreto, quando produzido com cinza de biomassa vegetal (CBV) em substituição parcial ao cimento, apresenta frente à ação de agentes agressivos, encontrado normalmente diluído em água ou em solos pantanosos e de minas de sal, levando a degradação do concreto, ao produzir etringita pela reação com os aluminatos, silicatos e hidróxidos de cálcio da matriz cimentícia.

\section{MATERIAIS E MÉTODOS}

\subsection{Caracterização dos materiais}

Foram utilizadas três faixas de areia (Grossa-Areia 1, Média-Areia 2 e Fina-Areia 3) para compor o traço determinado pelo empacotamento das partículas. Para o agregado graúdo foram utilizadas duas faixas de brita, a brita 0 ou pedrisco, de dimensão reduzida, variando de $4,8 \mathrm{~mm}$ a $9,5 \mathrm{~mm}$, e a brita número 1 , de dimensões entre 9,5 e $19 \mathrm{~mm}$. Os agregados foram caracterizados segundo sua granulometria de acordo com a NBR NM 248 [27] e massa específica dada pelas normas NBR NM 52 [28] e NBR NM 53 [29] para agregados miúdos e graúdos respectivamente. Na Figura 1 encontra-se a caracterização granulométrica de cada material usado no traço. 


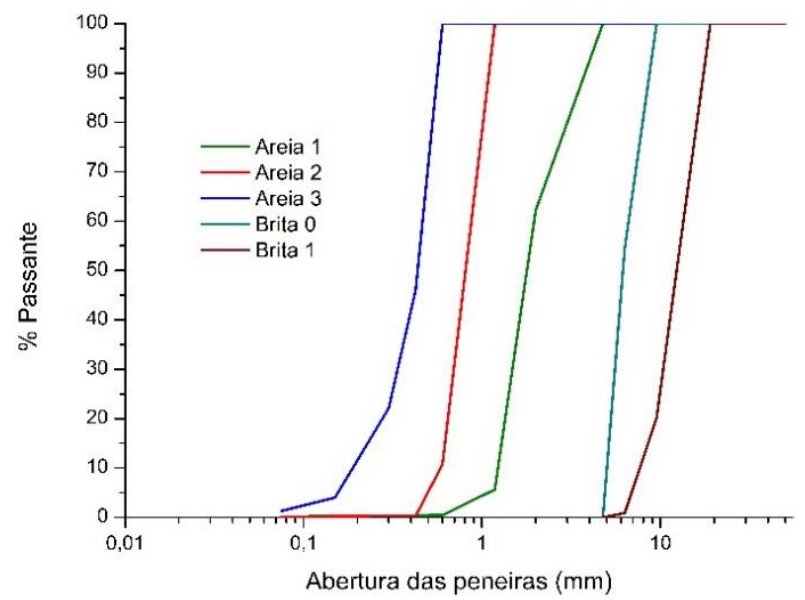

Figura 1: Granulometria dos agregados.

Na Tabela 1 apresentam-se os valores obtidos de massa específica para as areias 1,2 e 3, e brita 1 e 0.

Tabela 1: Resumo massas específicas dos materiais utilizados no traço.

\begin{tabular}{cc}
\hline MATERIAL & MASSA ESPECÍFICA $\left(\mathbf{g} / \mathbf{c m}^{3}\right)$ \\
\hline Areia 1 & 2,382 \\
Areia2 & 2,276 \\
Areia 3 & 2,131 \\
Brita 0 & 2,696 \\
Brita 1 & 2,733 \\
\hline
\end{tabular}

O cimento utilizado foi o CP II F-32, caracterizado através da técnica de espectrometria de fluorescência de raios X para análise química, conforme mostrado na Tabela 2 e granulometria à laser (Figura 2), em que foi utilizado um granulômetro da marca CILAS modelo 1090. A massa específica foi determinada a partir do regimento da NBR 16605 [30], sendo encontrado um valor de 2,948 g/cm³.

Tabela 2: Caracterização química do cimento CP II F-32.

\begin{tabular}{lccccccccccc}
\hline COMPOSTO & $\mathrm{CaO}$ & $\mathrm{SiO}_{2}$ & $\mathrm{Fe}_{2} \mathrm{O}_{3}$ & $\mathrm{SO}_{3}$ & $\mathrm{~K}_{2} \mathrm{O}$ & $\mathrm{TiO}_{2}$ & $\mathrm{SrO}$ & $\mathrm{V}_{2} \mathrm{O}_{5}$ & $\mathrm{ZnO}$ & $\mathrm{CuO}$ & Outros \\
\hline $\begin{array}{l}\text { PORCENTAGEM } \\
\text { PRESENTE (\%) }\end{array}$ & 79,191 & 11,769 & 3,799 & 3,048 & 1,473 & 0,432 & 0,096 & 0,046 & 0,039 & 0,034 & 0,075 \\
\hline
\end{tabular}

A cinza de biomassa vegetal (CBV) correspondeu a adição mineral implementada ao traço, disponibilizada pela empresa Irmãos Rolim Cerâmica, localizada no munícipio de São João do Rio do Peixe-PB. E por se tratar de um material pulverulento também foi realizado, como para o cimento, o ensaio de fluorescência de raios X, para análise química (Tabela 3) e granulometria à laser (Figura 2).

Tabela 3: Caracterização química da CBV.

\begin{tabular}{cccccccccccc}
\hline COMPOSTO & $\mathrm{CaO}$ & $\mathrm{K}_{2} \mathrm{O}$ & $\mathrm{SiO}_{2}$ & $\mathrm{SO}_{3}$ & $\mathrm{SrO}$ & $\mathrm{TiO}_{2}$ & $\mathrm{Fe}_{2} \mathrm{O}_{3}$ & $\mathrm{MnO}$ & $P_{2} \mathrm{O}_{5}$ & $\mathrm{Lu}_{2} \mathrm{O}_{3}$ & Outros \\
\hline $\begin{array}{c}\text { PORCENTAGEM } \\
\text { PRESENTE (\%) }\end{array}$ & 84,649 & 6,611 & 3,807 & 1,502 & 1,399 & 0,775 & 0,743 & 0,151 & 0,139 & 0,069 & 0,154 \\
\hline
\end{tabular}




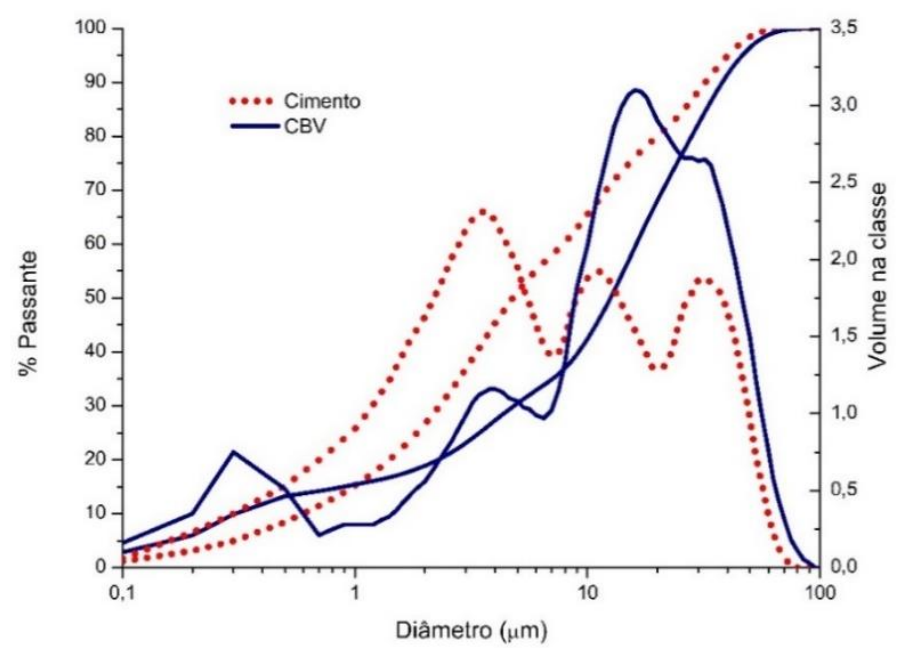

Figura 2: Granulometria do Cimento CP II F-32 e a da Cinza de biomassa vegetal.

Além desses materiais fez-se uso de aditivo plastificante, para reduzir a quantidade de água no traço de modo a permanecer com a proporção água/cimento, CEMIX 2000- VEDACIT. Segundo informações do fabricante esse apresenta composição básica de naftaleno sulfonado, massa específica equivalente a $1,19 \mathrm{~g} / \mathrm{cm}^{3}$ e consumo recomendado de 0,3 a $1,5 \%$ sobre a massa de cimento.

\subsection{Dosagem do concreto}

A fim de encontrar uma distribuição granulométrica virtual que se aproximasse do sistema real, porém de maneira otimizada, foi utilizado o modelo teórico de Alfred, também conhecido como Andreassen modificado [31]. A princípio foi feita a caracterização dos agregados quanto às suas granulometrias e massas específicas, descritas na Figuras 1 e Tabela 1, respectivamente. Os diâmetros máximos e mínimos dos agregados ensaiados foram respectivamente $19,0 \mathrm{~mm}$ e 0,075 mm. De posse desses valores realizou-se uma comparação entre as curvas geradas pela planilha desenvolvida por ARRUDA et al. [32] e pelo software Elkem Material Mix Analizer-EMMA para dosagem do concreto, com a curva do método de Alfred (Andreassen modificado), como mostram as Figuras 3 e 4 respectivamente, de forma a encontrar a distribuição que mais se aproxima do modelo ideal.

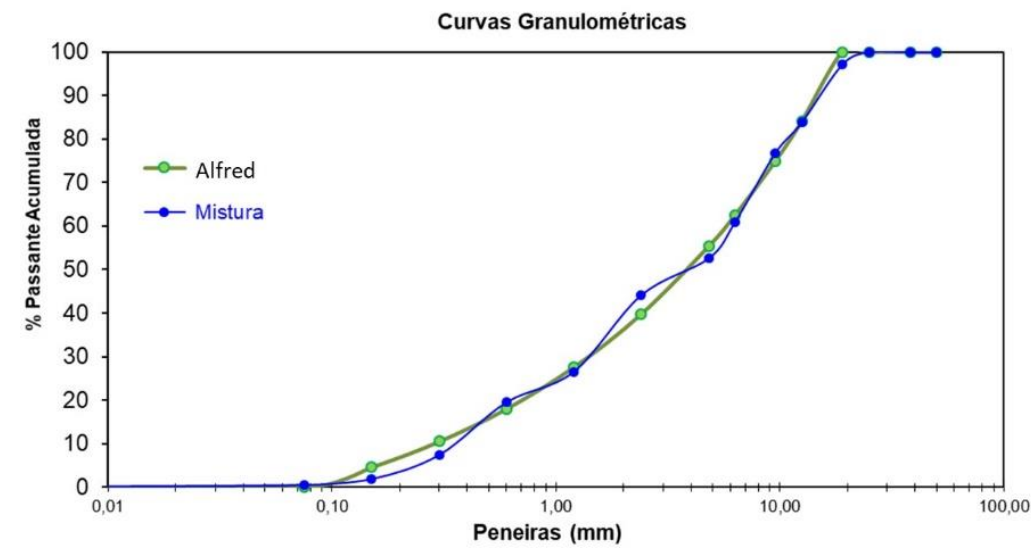

Figura 3: Curvas granulométricas virtual e do modelo matemático (Alfred), para $q=0,35$. 


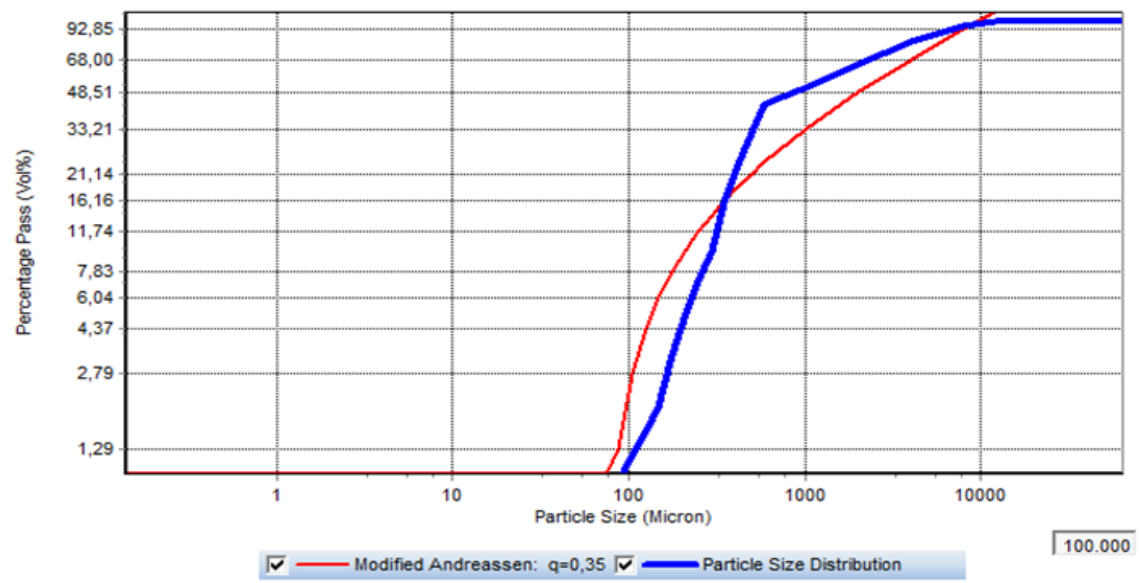

Figura 4: Distribuição granulométrica no software EMMA.

Ambas as ferramentas apresentam as porcentagens de cada agregado a ser utilizado, através do método dos mínimos quadrados, em que se determina a porcentagem individual de cada agregado na mistura para que se tenha o menor desvio em relação à curva do modelo (Alfred) escolhido para o empacotamento. Os dados de saída da planilha são os valores das proporções dos agregados na mistura de acordo com o menor desvio. Como as soluções admitem zero como resultado, caso a mistura não necessite de alguns desses agregados para compor um menor desvio, a solução poderá ser nula para esses agregados. Isso acontece no caso de curvas granulométricas semelhantes, que apresentam módulos de finura muito próximos.

Vale salientar que para o modelo de Alfred é necessário à utilização de um coeficiente de distribuição (q) [31]. Segundo SILVA, SEGADÃES e DEVEZAS [33], o valor de "q" igual a 0,37 resulta no melhor empacotamento de partículas esféricas, contudo para encontrar uma distribuição mais próxima do real optou-se pela adoção do valor 0,35, motivado por resultados dos trabalhos anteriormente desenvolvidos por HÜSKEN [34], YU et al. [35] e ARRUDA et al. [32], em que verificaram menores volumes de vazios em misturas (areias e britas) para os mesmos tipos de agregados utilizados no presente estudo.

Após o procedimento citado foi selecionada a distribuição fornecida com o auxílio da planilha de ARRUDA et al. [32] por essa apresentar uma curva mais próxima do modelo ideal de Andreassen. A Tabela 4 apresenta os valores encontrados para cada agregado na mistura, que foram utilizados para calcular o índice de vazios, necessário para a definição do traço do concreto.

Tabela 4: Proporções dos agregados no empacotamento.

\begin{tabular}{cccccc}
\hline AGREGADO & Areia 1 & Areia 2 & Areia 3 & Brita 0 & Brita 1 \\
\hline PROPORÇÃO $(\%)$ & 25,43 & 8,06 & 38,23 & 26,41 & 1,87 \\
\hline
\end{tabular}

De posse das proporções dos agregados empacotados e fazendo uso da NBR NM 45 [36] encontrou-se o índice de vazios da mistura, correspondendo a uma porcentagem de $29,41 \%$. Sabendo que o teor ideal de pasta no concreto seria aquele que preenchesse os vazios, tem-se que o volume de pasta foi determinado de acordo com este volume de vazios do esqueleto granular.

Segundo MEHTA e MONTEIRO [20], uma das formas de se alcançar um concreto com alto desempenho com consumo de cimento reduzido diz respeito a utilização de valores de relação a/c de 0,4 ou menos, de forma a encontrar pouca ou nenhuma permeabilidade, pois esta é uma propriedade procurada para garantir longa durabilidade, principalmente quando se tratar de estruturas expostas a ambientes agressivos.

No entanto é preciso encontrar o teor ideal de água que proporcione uma menor porosidade do material no estado sólido e que mantenha uma trabalhabilidade adequada ao uso. Tendo em vista essas imposições foram realizados testes de consistência com as proporções de agregados calculadas e a utilização de cimento, variando o consumo de água, entre os valores de 0,4 a 0,5, considerando a interação água/finos (a/f), sendo essa correspondente a razão entre a massa do líquido e a soma do cimento Portland com a cinza de biomassa vegetal. 


\subsection{Preparo, cura e moldagem dos corpos de prova}

O concreto foi misturado em uma betoneira, iniciando com o agregado graúdo e metade da água, após cerca de 30 segundos de mistura foram adicionadas as areias, da mais grossa para a mais fina, em seguida o cimento e a cinza de biomassa vegetal, esperando a homogeneização da mistura para inserir o restante da água com o aditivo plastificante. A betoneira permaneceu ligada entre 5 e 6 minutos.

Devido a disponibilidade da cinza e verificação da redução da trabalhabilidade do concreto, optou-se por reduzir o cimento em 10, 15 e $20 \%$ da massa, cada traço sendo identificado por T10, T15 e T20, respectivamente, além do traço de referência denominado T0. Após a mistura ser finalizada foram moldados 26 corpos de provas cilíndricos $(10$ x 20) $\mathrm{cm}$ para cada traço, em conformidade com a NBR 5738 [37], realizando o adensamento manual para todos. Decorridas 24 horas da moldagem estes foram desmoldados e identificados, para posterior processo de cura. No total foram moldados 104 corpos de prova cilíndricos, 26 para cada traço, onde 2 eram destinados para o ensaio de absorção. Metade deste total foi submersa em tanque de água saturada com cal.

O restante dos corpos de prova (52) foi colocado em tanque adaptado contendo solução de sulfato de sódio, preparada no dia anterior a imersão dos corpos de prova. A solução foi preparada de acordo com as etapas indicadas na NBR 13583 [38], trocada a cada 20 dias e mantida fechada de forma a manter a concentração de sulfato constante.

Para a verificação da expansão geométrica foram moldados corpos de provas prismáticos de argamassa (4 x 4 x 16) cm, seguindo as recomendações da NBR 13583 [38], utilizando o traço e relação água/finos definidos para o concreto, retirando apenas o agregado graúdo. Os corpos de prova de argamassa foram desmoldados após 24 horas, sendo todos submetidos a uma cura em solução de cal saturada por um período de 12 dias, conforme indicado em norma. Posteriormente os mesmos foram divididos em duas classes, sendo uma exposta a solução agressiva de íon sulfato e a outra permanecendo na solução de cal saturada [39]. Para cada traço foram moldados 6 corpos de prova, totalizando 24, destinando 3 para cada tipo de solução.

\subsection{Ensaios destrutivos e não destrutivos}

\subsubsection{Ensaio de Kantro}

A compatibilidade do aditivo com o cimento foi verificada utilizando o ensaio do mini abatimento descrito por KANTRO [40]. Existe uma grande semelhança entre o ensaio de Kantro e o de abatimento do concreto, visto que as proporções das dimensões do molde tronco-cônico são as mesmas [41]. O molde do tronco de cone foi confeccionado em impressora 3D e apresentou as dimensões padrões determinadas por Kantro [40], diâmetro superior, inferior e altura de $19 \mathrm{~mm}, 38 \mathrm{~mm}$ e $57 \mathrm{~mm}$ respectivamente. Além deste utilizou-se uma mesa nivelada com uma folha de papel milimetrado apoiada sob a placa de vidro.

Preparou-se pastas de cimento para diferentes teores do aditivo, tendo como referência os limites propostos pelo fabricante. Foi utilizado para cada pasta $200 \mathrm{~g}$ de cimento, com relação água/aglomerante já definida; como a quantidade de pasta era pequena adaptou-se o misturador com copo para realizar a mistura. Esta permaneceu em mistura entre 2 e 3 min [40]. Após a preparação da pasta, esta foi inserida no molde, em seguida este foi removido esperando a estabilização da pasta. Com o auxílio de um paquímetro foram medidos dois diâmetros perpendiculares, calculando o valor médio que representa o espalhamento da pasta ensaiada. Foram preparadas pastas com adição de cinza de biomassa vegetal e testadas para cada porcentagem de aditivo analisada, que consistiram em $0,1 \%, 1,2 \%, 1,5 \%$ e $2 \%$, sabendo que o recomendado pelo fabricante é não ultrapassar a faixa de $1,5 \%$.

\subsubsection{Ensaio de consistência (Slump Test)}

De acordo com a NBR NM 67 [42] foi realizado o ensaio do abatimento de tronco de cone, mais conhecido como slump test, a fim de conhecer a consistência do concreto. Ao término do preparo de cada um dos quatro traços, era executado o ensaio, realizando o preenchimento do tronco de cone em 3 camadas, adensadas manualmente através de 25 golpes.

\subsubsection{Ensaio de resistência (Compressão axial)}

A fim de conhecer as variações de resistência resultantes da redução do cimento e substituição por cinza de biomassa vegetal, foi realizado o ensaio de compressão axial dos corpos de prova cilíndricos, em conformi- 
dade com a NBR 5739 [43]. Foram confeccionados 26 corpos de prova para cada traço, 24 foram destinados ao ensaio de compressão axial, sendo 12 curados em água saturada com cal e 12 em solução de sulfato de sódio. Rompendo nas idades de 21, 28, 56 e 80 dias, três corpos de cada classe.

\subsubsection{Expansão geométrica}

De forma a investigar a ação do sulfato no concreto com redução de cimento foram confeccionados 24 corpos de prova prismáticos, 6 para cada traço, onde 3 eram submetidos a cura normal e o restante, na solução de sulfato de sódio anidro. A geometria das peças prismáticas foi verificada aos 14, 28 e 42 dias após a exposição a condição de cura final. Utilizando-se de um paquímetro verificou-se a variação nas dimensões do corpo de prova, sempre posicionados no mesmo ponto, nas idades indicadas. Estes eram retirados da solução exposta, colocados sobre bancada e deixados por aproximadamente 10 minutos para estabilização da temperatura.

Terminado o processo, eles eram recolocados nas soluções de cura, as quais eram verificadas de forma a manter o volume constante. Para execução deste ensaio foi utilizada como base a NBR 5738 [38]. O resultado se dá pelo aumento ou diminuição da expansão da argamassa devido ao ataque do sulfato de sódio, em relação à expansão da argamassa submetida à cura normal, expresso em porcentagem, segundo a NBR 5738 [38], e corresponde à diferença entre a expansão média das barras curadas em solução agressiva de sulfato de sódio pela das barras curadas em solução de água saturada com cal.

\subsubsection{Absorção de água e índice de vazios}

Para determinar a capacidade de absorção de água e o índice de vazios do concreto no estado endurecido, utilizou-se a NBR 9778 [44]. Conforme mencionado, foram moldados 2 corpos de prova de cada traço para execução deste ensaio, o qual consistiu inicialmente na secagem destes na estufa por 72 horas. Depois de retirados foram mantidos imersos em água por mais 72 horas. Em seguida colocados em recipiente com água em ebulição e volume constante por 5 horas. Passado esse tempo permaneceram no recipiente até esfriarem e tiveram as massas determinadas em balança hidrostática. Por fim, retirado o excesso de água com uma toalha, novamente tiveram suas massas determinadas. A cada etapa realizada registrou-se a massa do elemento sendo possível, de posse do uso das equações da NBR 9778 [44], calcular os valores de absorção de água e índice de vazios do concreto estudado.

\section{RESULTADOS}

\subsection{Avaliação da atividade pozolânica da cinza}

Por meio do ensaio de resistência à compressão simples, desenvolvido em concordância com a NBR 5752 [45], foi possível determinar o índice de atividade pozolânica dos corpos de prova de argamassa contendo adição de cinza. Na Tabela 5 encontram-se os resultados da resistência a compressão da argamassa A, apenas com cimento Portland e a argamassa B com adição de CBV.

Tabela 5: Resistências médias aos 28 dias de argamassas com e sem adição de CBV.

\begin{tabular}{cccc}
\hline IDADE (DIAS) & CORPO DE PROVA & ARGAMASSA A (MPA) & ARGAMASSA B (MPA) \\
\hline & CP1 & 32,39 & 22,95 \\
CP2 & 33,43 & 20,77 \\
CP3 & 32,18 & 21,18 \\
28 & CP4 & 33,33 & 21,40 \\
& CP5 & 30,94 & 20,35 \\
& CP6 & 35,92 & 20,77 \\
& Resistência média & 33,04 & 21,23 \\
\hline
\end{tabular}

De acordo com a Equação 1 foi calculado o índice de atividade pozolânica do Cimento Portland, apresentando o valor de 64,27\% [45]. A NBR 12653 [46] diz que para ser considerado um material pozolânico, o índice de desempenho aos 28 dias deve apresentar um valor superior a 90\%. Sendo assim, a amostra com CBV não atingiu o limite mínimo. 


$$
I_{\text {cimento }}=\frac{f_{c} B}{f_{c} A} \cdot 100
$$

Em que,

$f_{c} B$ : Resistência média aos 28 dias dos corpos de prova com adição de material pozolânico;

$f_{c} A$ : Resistência média aos 28 dias dos corpos de prova apenas com cimento CP II-F-32;

Quanto à composição química, a NBR 12653 [46] estabelece requisitos para verificação da atividade pozolânica dos materiais: a soma dos óxidos de silício, alumínio e ferro ( $\mathrm{SiO} 2+\mathrm{Al} 2 \mathrm{O} 3+\mathrm{Fe} 2 \mathrm{O} 3)$ deve ser maior que $70 \%$ e teor de óxido de enxofre (SO3) menor que 5\%. De acordo com a Tabela 3, a soma dos óxidos está muito abaixo do estabelecido pela norma, 4,55\%. Assim, por este critério, não se espera que esta adição contribua ativamente. Por fim, a análise de DRX (Figura 5) apresenta picos bem definidos de calcita, e outros menores de ferro demonstrando a baixa reatividade do material além da ausência expressiva de sílica o que reafirma os resultados da argamassa de cimento Portland e a análise dos óxidos caracterizando-se assim um material não pozolânico.

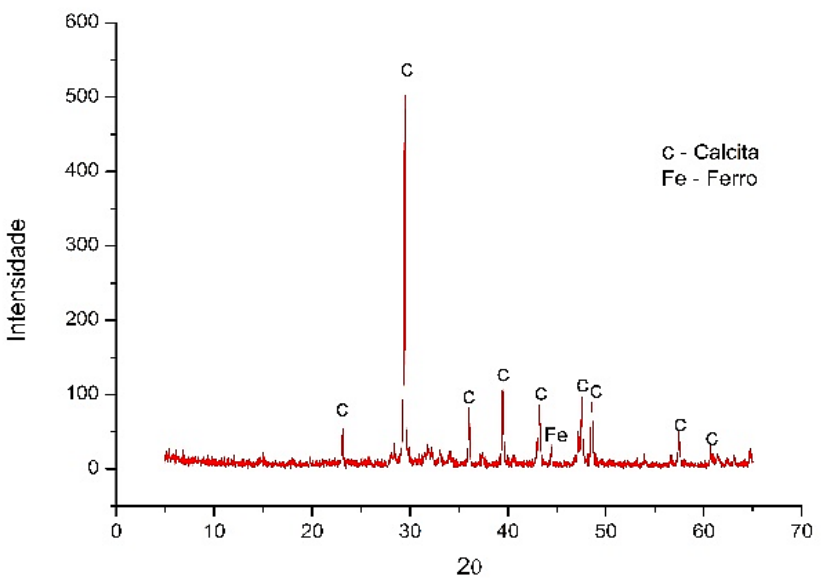

Figura 5: DRX da CBV.

\subsection{Traço Final}

Para composição final do traço foram associados os resultados do esqueleto granular dos agregados e dos demais finos a partir do índice de vazios, além da composição da pasta, verificando a compatibilidade aditivo/finos por meio do ensaio de KANTRO [40] e o consumo de água, tomando como base valores de testes pilotos do ensaio de abatimento.

A partir das proporções dos materiais determinadas através da ferramenta de Arruda et al. [32], preparou-se uma mistura, na qual foi verificado o volume de vazios da mesma, equivalente a 29,41\%, correspondente ao valor a ser preenchido por pasta de cimento. LONDERO [47] desenvolveu dois tipos de traço, o primeiro com a porcentagem de pasta igual a de vazios e um segundo com ausência de pasta para preencher os espaços livres, observando que aquele com a quantidade exata apresentava melhor eficiência e comportamento mecânico, no entanto dificultava a trabalhabilidade. Nesse sentido, de forma a encontrar o traço que garantisse boa trabalhabilidade e pela escassez de trabalhos que tenham estudado acréscimos ideais, foram testados os volumes de pasta como sendo o volume de vazios acrescidos de $10 \%$ e $15 \%$.

Para verificação da quantidade ideal a ser acrescida tomou-se como base os resultados obtidos nos testes pilotos de abatimento do tronco de cone dado pela NBR NM 67 [42]. Esse também auxiliou na verificação da relação final água/finos estabelecidos a partir do teste de compatibilidade e fixação da proporção de aditivo obtida pelo ensaio de KANTRO [40].

Dentro da faixa pré-estabelecida de 0,4 a 0,5 da relação água/finos, foram utilizados três valores, correspondentes a 0,4, 0,45 e 0,5, variando o teor de aditivo. Na verificação dessas relações observou-se que para 0,5 de a/f, independente da porcentagem de aditivo a pasta apresentava exsudação e desuniformidade nos diâmetros (Figura 6), tornando esse valor inapto dentro dos critérios de aceitabilidade do ensaio. Logo para maior representatividade optou-se por analisar um valor intermediário entre 0,45 e 0,5 , tendo sido ado- 
tado 0,48 .

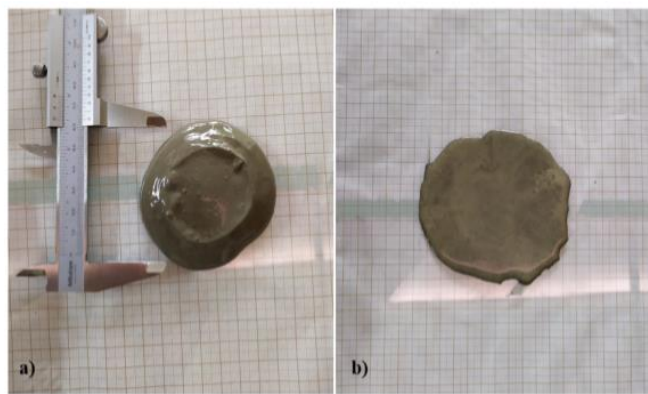

Figura 6: a) Aferição dos diâmetros perpendiculares da pasta; b) Desuniformidade dos diâmetros e exsudação da pasta.

O ensaio de KANTRO [40] foi realizado com uma relação a/f de 0,48 , onde se verificou que o traço de referência e o T10, a partir do valor de 1,2\% de plastificante, apresentavam crescimento na área de espalhamento, a qual aumentava de forma irregular e ocorria a exsudação da pasta (Figura 6b), o que para MONTE e FIGUEIREDO [41] caracteriza uma das vantagens do método. Quanto aos traços T15 e T20, o valor da área permaneceu constante para adições maiores que $1,2 \%$, no entanto não se observou nenhuma incompatibilidade da cinza com o aditivo (Figura 7).

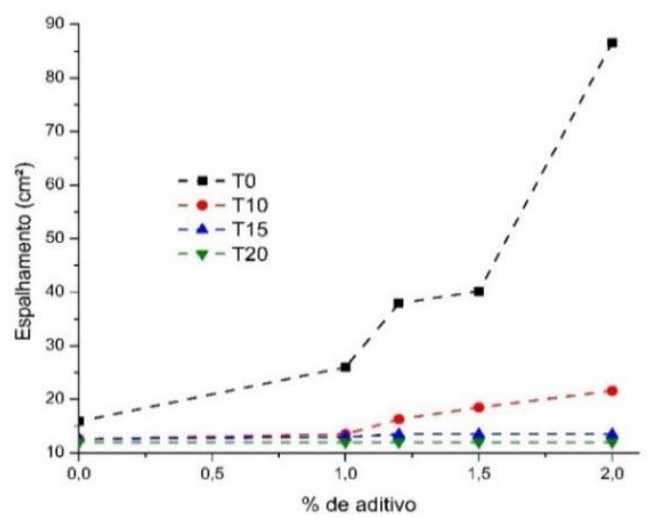

Figura 7: Comportamento das misturas frente a variação da porcentagem do aditivo.

Adotando o valor de 0,48 encontrado no ensaio de KANTRO [40] para a relação a/f foram realizadas misturas variando a porcentagem do aditivo em $1 \%$ e $1,2 \%$, e a porcentagem de pasta de $10 \%$ e $15 \%$ do volume de vazios, como citado anteriormente. Observou-se uma maior eficiência no traço executado com 1,2\% de aditivo e o volume de pasta correspondente a $15 \%$, encontrando maiores valores de abatimento e melhor trabalhabilidade. Reunindo os valores dos consumos de cada material utilizado, efetuou-se um quociente entre o consumo do cimento e cada elemento que iria compor o traço, como exemplificado na Tabela 6 para a produção de um metro cúbico de concreto, resultando no traço final de 1:0,96:0,31:1,45:1:0,07 e relação a/f de 0,48 .

Tabela 6: Traço Final.

\begin{tabular}{ccc}
\hline MATERIAL & CONSUMO $\left(\mathbf{K G} / \mathbf{M}^{\mathbf{3}}\right)$ & TRAÇO FINAL \\
\hline Areia 1 & 398,41 & 0,96 \\
Areia 2 & 126,28 & 0,31 \\
Areia 3 & 598,95 & 1,45 \\
Brita 0 & 413,76 & 1,00 \\
Brita 1 & 29,30 & 0,07 \\
Cimento & 413,56 & 1,00 \\
\hline
\end{tabular}


WASSERMANN, KATZ e BENTUR [48] produziram concretos avaliando a demanda de água, o uso de aditivo e a redução do volume de pasta, de modo consequente a redução do volume de cimento, para diversas estruturas e parâmetros de durabilidade, sendo encontrados resultados satisfatórios em concretos com consumos de cimento variando entre 230 a $450 \mathrm{~kg} / \mathrm{m}^{3}$ e relação água/cimento de 0,45 a 0,7. Essas faixas indicadas pelos autores serviram como base para aceitação do consumo de cimento encontrado no traço final

\subsection{Caracterização do concreto no estado fresco}

$\mathrm{Na}$ verificação das características do concreto no seu estado fresco o principal parâmetro observado corresponde a consistência deste por meio do abatimento do tronco de cone, realizado conforme a NBR NM 67 [42], em que a Figura 8 apresenta os resultados obtidos para cada teor de substituição analisado. Vale ressaltar que para todas as misturas manteve-se o mesmo percentual de aditivo, como também a mesma relação a/f.

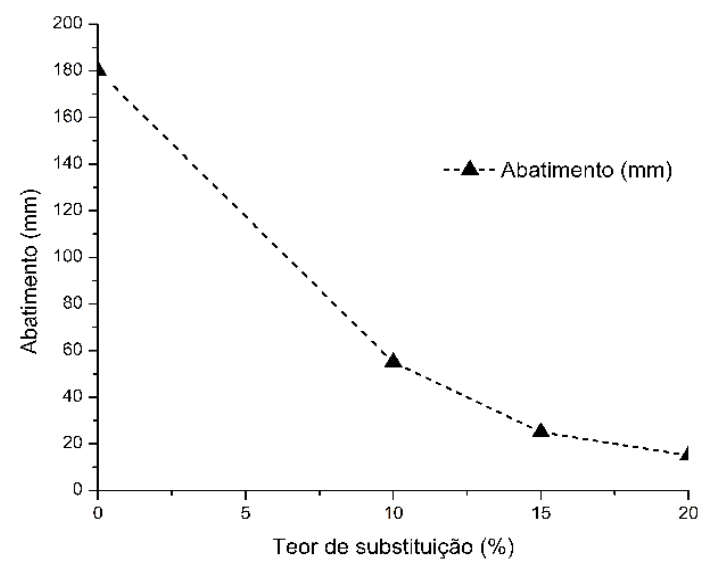

Figura 8: Abatimento do tronco de cone para os traços analisados.

Observa-se que houve uma grande interferência da cinza no abatimento do concreto, reduzindo 69,44\%, $86,11 \%$ e $91,66 \%$, para os traços T10, T15 e T20, respectivamente, em comparação ao traço de referência, evidenciando que estas incorporações influenciam na trabalhabilidade do concreto. Segundo SAMPAIO [49] o processo de produção da cinza faz com que sua absorção de água seja maior do que para manter a consistência do concreto, consequentemente o tornando mais seco e com menor trabalhabilidade. A composição granulométrica da cinza, por caracterizar o material como fino, também se relaciona a uma maior tendência de reter água [50].

\subsection{Expansão geométrica}

Foram feitas leituras nas idades de 14, 28, 42 dias sendo os resultados correspondentes a diferença das expansões médias de cura normal e em sulfato para cada período e mistura são apresentados na Figura 9.

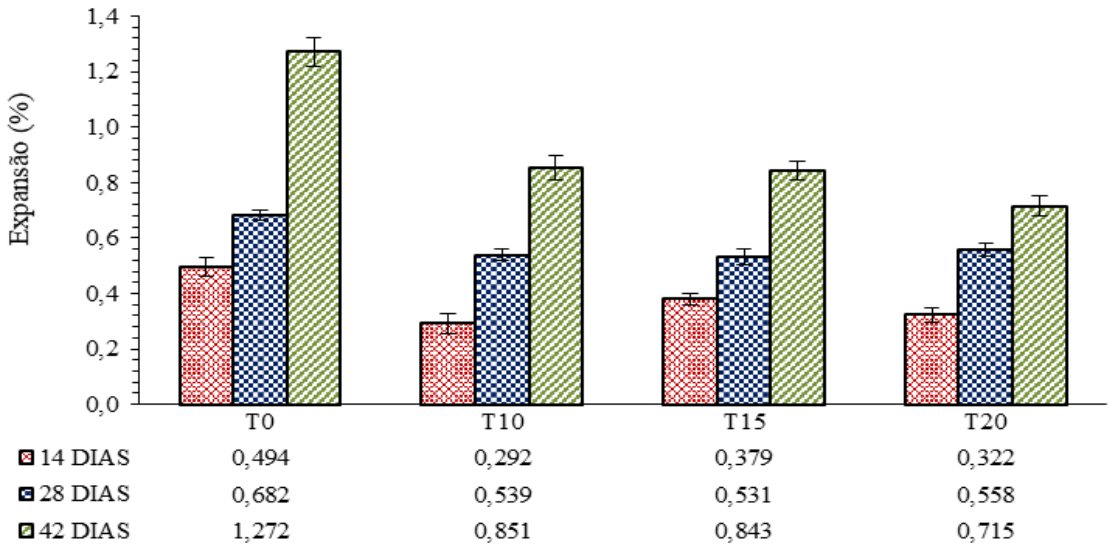

Figura 9: Expansão média em porcentagem das argamassas devido ao ataque do sulfato. 
Inicialmente verifica-se que existe um aumento na expansão geométrica das amostras à medida que as idades avançam, comportando-se de maneira inversa quando comparados os valores para os traços com adição de cinza e o de referência. Constata-se que inicialmente o traço T10 foi o que exibiu menor expansão, no entanto não houve um padrão para as demais misturas na mesma idade, visto um decrescimento e posterior crescimento nas amostras T15 e T20, respectivamente. Diferentemente do que aconteceu aos 28 dias, em que todas as proporções apresentaram uma proximidade nos valores obtidos, sendo somente aos 42 dias, observado um padrão na redução da expansão.

Existem fatores físico-químicos que influenciam na dinâmica do ataque ao sulfato, levando ao comprometimento da integridade de argamassas ou concretos. Dentro das dimensões físicas predomina o processo de caminhamento da solução sulfatada para o interior do compósito. Já no que se trata dos processos químicos, esses possuem maior complexidade, dando destaque às reações ligadas a presença de íons sulfato [20].

Nessa perspectiva química dos fatores que contribuem para a baixa expansão geométrica da argamassa pode-se mencionar a redução da disponibilidade de $\mathrm{C}_{3} \mathrm{~A}$ nas misturas acrescidas de $\mathrm{CBV}$, sendo essas T10, T15 e T20. Esse composto é parte integrante das fases anidras do cimento, desencadeando diversos produtos durante o processo de hidratação, como as famílias dos aluminatos, a etringita e o monossulfato [51, 26].

$\mathrm{O} \mathrm{C}_{3} \mathrm{~A}$ reage junto com o sulfato formando cristais aciculares denominados de trissulfoaluminato de cálcio ou etringita, cujo crescimento irá promover um aumento nas tensões internas do corpo provocando a expansão da pasta, tendo como consequência o aparecimento de fissuras na mesma [51].

No que se diz respeito ao padrão de estabilização verificado aos 28 dias de exposição, Viscaldi e Silva [52] correlacionam esse fato ao preenchimento dos poros do concreto, que levam a não renovação do sulfato e consequentemente dificultam a propagação de novas reações químicas. Situação que pode ser reafirmada quando ainda é observado um aumento da expansão após a segunda leitura, em que ocorreu a substituição da solução sulfatada, renovando os íons do meio, facilitando a penetração dos poros restantes.

À medida em que as amostras foram expostas a solução agressiva de sulfato de sódio, percebeu-se alterações visuais nas superfícies das mesmas, desde mudanças na coloração, associados a um destacamento nas faces dos corpos de prova, como apresentado na Figura 10 [21].

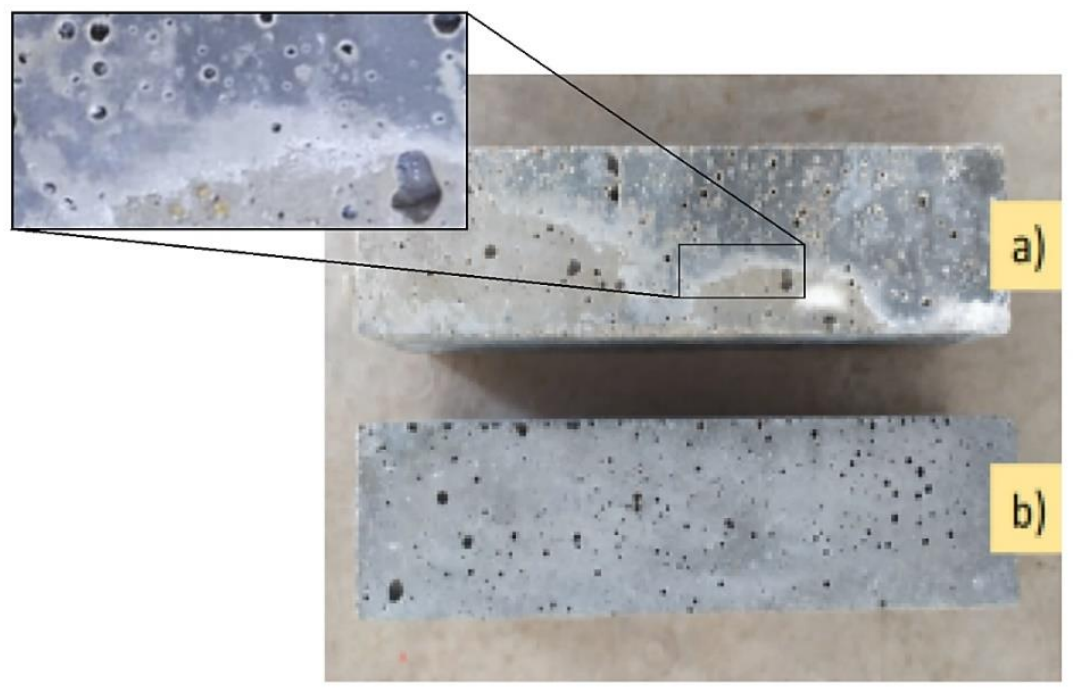

Figura 10: a) Argamassa atacada pelo sulfato em comparação a b) argamassa curada em solução de água saturada com cal.

Essa deterioração provocada pelo ataque de sulfatos, como afirma Batista [53] está relacionada a neoformações, consequência da interação entre os íons sulfato e as fases de hidratação, que possuem maior volume molecular, menor coesão, que minimizam a integridade física do material. 


\subsection{Absorção de água e índice de vazios}

Os resultados obtidos no ensaio de absorção de água por imersão, executado de acordo com a NBR 9778 [44], encontram-se representados na Figura 11 para concreto em cura saturada com hidróxido de cálcio e submersos em solução de sulfato de sódio anidro.

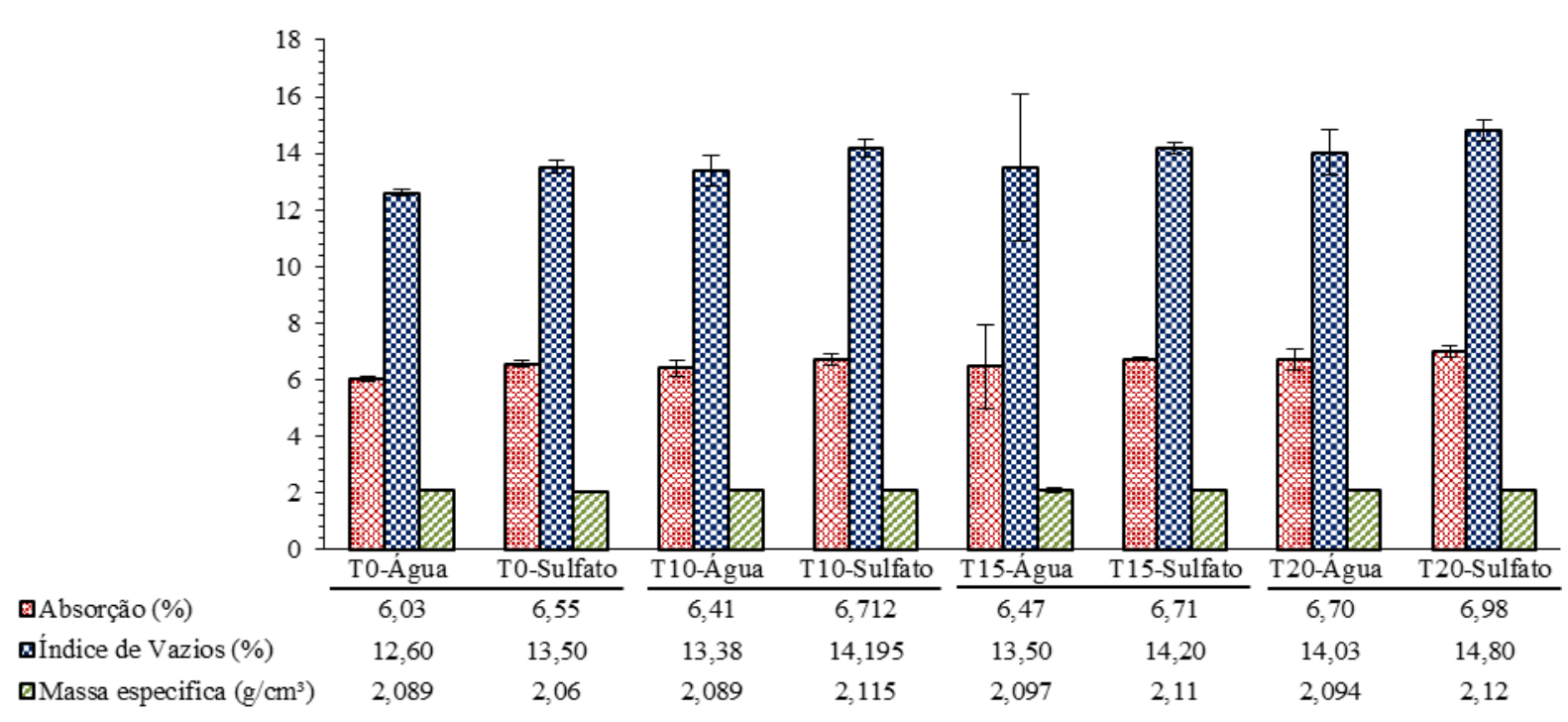

Figura 11: Absorção, índice de vazios e massa específica das amostras em solução de água saturada com cal e sulfato de sódio anidro.

É possível observar que a CBV provocou no concreto uma variação insignificante de massa específica, apresentando-se aproximadamente $2,10 \mathrm{~g} / \mathrm{cm}^{3}$, corroborando os estudos realizados por PAULA et. al [54] que não encontrou variações significativas em adições de até $30 \%$ de cinzas.

Tratando-se da absorção, os traços com adição de CBV, apresentaram um crescimento sutil, em relação ao T0, sendo esse proporcional ao aumento do teor de cinza, em ambos os processos de cura. Observando-se também, que para as amostras expostas ao sulfato além do aumento já referido foi constatada uma variação crescente em relação ao valor da absorção dessas e suas correspondentes em cura convencional. Esse comportamento vai de encontro aos estudos de CORDEIRO [55] e MERCADO e TOMMASSELI [56] em que concretos com adições tendem a apresentar uma maior absorção em comparação aos valores de referência. Em se tratando de cinzas, esse fato é justificado pela presença de matéria orgânica na sua composição, na forma de carbono livre que em geral pode ser proveniente de uma combustão ineficiente.

No que se refere ao volume de vazios das misturas, esses apresentam-se de forma similar para os ambos processos de cura, com valores proporcionais ao aumento da absorção. Segundo HOPPE FILHO et al [18] argamassas e concretos acrescidos de adições minerais podem levar a modificação das dimensões dos poros e suas interconectividades, característica provocada pelas alterações microestruturais causadas pelas adições na matriz hidratada, , como observado na Figura 12, influenciando a penetração da solução para o interior do material.

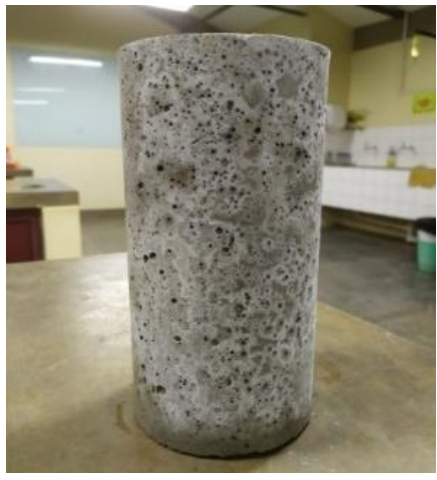

Figura 12: Visualização dos poros na superfície do concreto. 
Comparando os dados de expansão e índice de vazios pode-se perceber que ambos possuem relação contrária, à medida que a expansão diminui o índice de vazios aumenta. Uma das possíveis causas que leva a esse acontecimento é apresentada por FILHO [57] o qual afirma que uma maior quantidade de poros pode acomodar etringitas formadas, reduzindo a possibilidade de expansões e fissurações, diferente do que ocorre em uma matriz compacta e pouco porosa.

\subsection{Resistência a compressão}

A Figura 13 sumariza os resultados para o ensaio de compressão axial obtidos para os traços T0, T10, T15 e T20, nos dois tipos de cura estudados, nas idades de 21, 28, 56 e 80 dias.

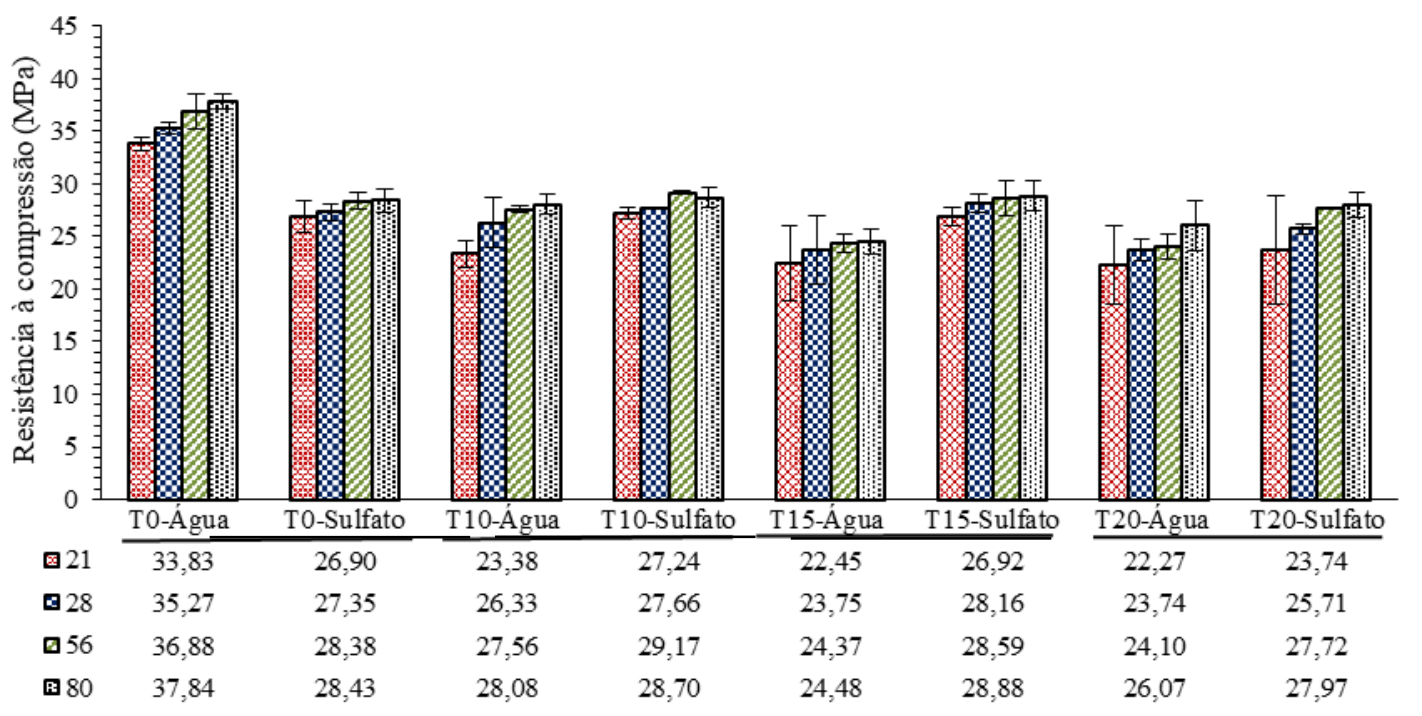

Figura 13: Resistência média a compressão dos traços estudados em cura normal e de solução saturada.

Pode-se constatar inicialmente que os traços desenvolvidos pelo empacotamento das partículas resultaram em resistências iniciais e características aceitáveis dentro dos limites estabelecidos pela NBR 12655 [58], considerando uma classe de agressividade ambiental I. Essa exige um valor superior a $20 \mathrm{MPa}$, alcançados em todos os casos.

Na Figura 14 é observada a variação percentual de resistência dos traços elaborados com CBV em comparação ao traço de referência, em que é perceptível um decréscimo uniforme na resistência daqueles providos de adição que foram submetidos à cura normal. Reagindo de maneira contrária, as amostras submetidas à solução sulfatada apresentam um acréscimo de resistência, salvo a mistura executada com $20 \%$ de adição de cinzas, que não manteve um comportamento similar aos demais traços, apresentando redução de resistência em ambos os processos de cura. 


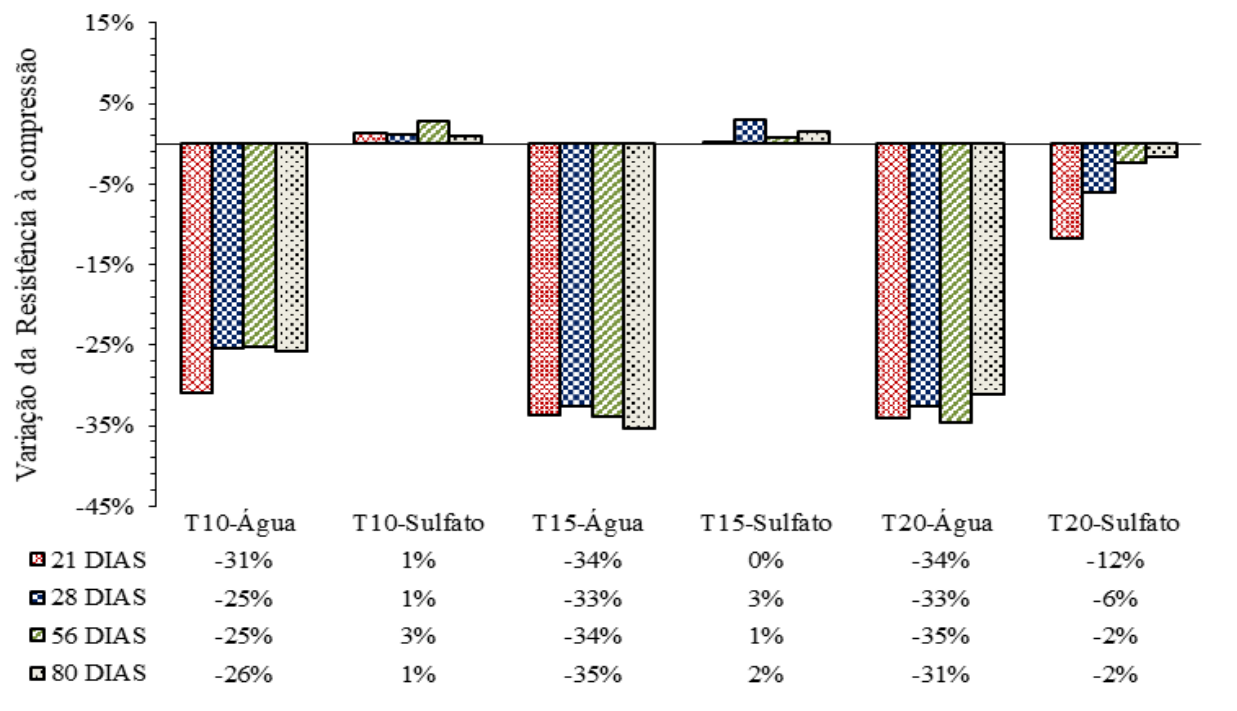

Figura 14: Variação percentual dos traços com adição de CBV em relação ao traço de referência.

Uma das possíveis razões para perda de resistência, mantida a relação a/f, se refere ao consumo de cimento utilizado para cada traço, já que a sua redução acarretará no baixo volume dos produtos de hidratação. Uma vez que alterações nas quantidades dos compostos que formam a fase anidra do cimento provocam modificações significativas no comportamento mecânico da matriz [57].

Adições com alto teor de sílica, por exemplo, ao entrarem em contato com a matriz e reagirem com o hidróxido de cálcio presente na pasta formam uma quantidade extra de silicato de cálcio hidratado que corresponde ao principal responsável pela resistência à compressão de uma matriz cimentícia [59]. O baixo teor desse componente é observado na adição estudada, que apresenta proporções de sílica na ordem de 3,807\%, como anteriormente apresentado na composição química do material presente na Tabela 3, podendo ser uma das razões que levaram a redução da resistência para os traços T10, T15 e T20 quando submetidos à cura convencional.

No que se refere ao comportamento do desempenho mecânico para os traços T10 e T15, que apresentaram um aumento nas resistências quando submetidas ao sulfato, essa pode ser justificada pelas proporções de aluminatos presentes na pasta, levadas pela redução do teor de cimento. O contato do concreto com esse componente acarretará em modificações da química do sistema, onde ocorrerá a formação do monossulfoaluminato, com uma expansão insignificante, além do refinamento da estrutura dos poros, dificultando a difusibilidade iônica. Logo o baixo teor de $\mathrm{C}_{3} \mathrm{~A}$ e a baixa liberação de $\mathrm{Ca}(\mathrm{OH})_{2}$ durante o processo de hidratação, melhoram a resistência ao sulfato do concreto, visto que são componentes essenciais para reagir com o íon e formar a etringita expansiva [60].

Nenhuma das misturas com adição de CBV apresentou valores altos de expansão, guiados pela hipótese de que mesmo com a formação de etringita, essa não se dava de forma suficiente a provocar expansões significativas [57]. Além disso, como já mencionado, o crescimento no consumo de CBV induz a um aumento da porosidade e uma acomodação dessas etringitas formadas, que pode ter levado os traços T10 e T15, que possuem um menor índice de vazios quando comparados ao T20, apresentarem uma maior densificação e consequentemente um melhor desempenho mecânico.

\section{CONCLUSÕES}

Os traços elaborados com cinza, mesmo essa não apresentando o índice de pozolanicidade preconizado, apresentaram bom desempenho, até o teor de $15 \%$, quando submetidos à cura em solução sulfatada, podendo ser aplicados em ambientes agressivos respeitando as suas classes de exigência. Esse teor de $15 \%$ reduz o consumo de cimento em até $60 \mathrm{~kg}$ por metro cúbico de concreto, no entanto essa redução também é vista nos valores de resistência, sendo necessária haver uma avaliação da compensação de acordo com a aplicação desejada, uma vez que o seu desempenho frente a ação de agentes agressivos mostrou-se satisfatório.

Vale ressaltar que as cinzas se mostraram eficientes quando analisadas as expansões médias das amostras em sulfato de sódio, comparadas aos traços de referência, mesmo essas absorvendo mais água e tornando o concreto mais poroso. Os resultados obtidos para o traço de $20 \%$ de adição de CBV, apresentaram-se posi- 
tivos em relação a expansão geométrica dos corpos de prova, mas não se comportaram de maneira eficiente mecanicamente, podendo ser utilizado desde que não seja exigida uma resistência igual a encontrada nos corpos de prova contendo $100 \%$ de cimento como aglomerante.

\section{BIBLIOGRAFIA}

[1] KLEE, H., "Cement Sustainability Initiative: Cement Industry Energy and $\mathrm{CO}_{2}$ Performance "Getting the Numbers Right"”. Washington, United States, WBCSD, 2009.

[2] CAO, Z., SHEN, L., LIU, L., et al., "Analysis on major drivers of cement consumption during the urbanization process in China", Journal of Cleaner Production, v. 133, pp. 304-313, May, 2016.

[3] CASTRO, A. L.; LIBORIO, J. B. L.; PANDOLFELLI, V. C. "A influência do tipo de cimento no desempenho de concretos avançados formulados a partir do método de dosagem computacional", Cerâmica, v. 57, n. 341, pp. 10-21, Mar, 2011.

[4] SNIC, "A indústria do cimento no cenário das mudanças climáticas", 2018. [Online]. Disponível em: http://snic.org.br. Acessado: 10-maio-2019.

[5] UWASU, M. ; HARA, K.; YABAR, H. "World cement production and environmental implications", Environmental Development, v. 10, n. 1, pp. 36-47, Apr, 2014.

[6] BERENGUER, R. A., CAPRARO, A. P. B., MEDEIROS, M. H. F., et al., "Sugar cane bagasse ash as a partial substitute of Portland cement: Effect on mechanical properties and emission of carbon dioxide", Journal of Environmental Chemical Engineering, v. 8, e103655, Apr, 2020.

[7] MOUMIN, G., RYSSEL, M., ZHAO, L., et al., "CO2 emission reduction in the cement industry by using a solar calciner”, Renewable Energy, v. 145, pp. 1578-1596, Jan, 2020.

[8] GAO, T., SHEN, L., SHEN, M., et al., "Analysis on differences of carbon dioxide emission from cement production and their major determinants", Journal of Cleaner Production, v. 103, pp. 160-170, Set, 2015.

[9] MEHDIPOUR, I., KHAYAT, K.H., "Understanding the role of particle packing characteristics in rheophysical properties of cementitious suspensions: A literature review", Construction and Building Materials, v. 161, pp. 340-353, Feb, 2018.

[10] WORRELL, E., PRICE, L., MARTIN, N., et al., "Carbon dioxide emissions from the global cement industry", Annual Review of Energy and the Environment, v. 26, pp. 303-329, Jun, 2001.

[11] COSTA, E. B., NOBRE, T. R. S., GUERREIRO, A. Q., et al., "Clínquer Portland com reduzido impacto ambiental", Ambiente Construído, v. 13, n. 2, pp. 75-86, Jun, 2013.

[12] KULOVANÁ, T., VEJMELKOVÁ, E., KEPPERT, M., et al., "Mechanical, durability and hygrothermal properties of concrete produced using Portland cement-ceramic powder blends", Structural Concrete, v. 17, n. 1, pp. 105-115, Aug, 2016.

[13] ZHAO, Y., GAO, J., LIU, C., et al., "The particle-size effect of waste clay brick powder on its pozzolanic activity and properties of blended cement", Journal of Cleaner Production, v. 242, e118521, Jan, 2020.

[14] BARBOZA, L.S; ALMEIDA FILHO, F. M., "Concreto autoadensável com baixo consumo de cimento: impacto da redução do consumo de cimento na resistência à compressão", Matéria, v. 23, n. 3, e12195, Oct, 2018.

[15] DAMTOFT, J. S., "Sustainable development and climate change initiatives", Cement and Concrete Research, v. 38, n. 2, pp. 115-127, Feb, 2008.

[16] KAPELKO, A., "Possibilities of cement content reduction in concretes with admixture of superplasticiser SNF”, Journal of Civil Engineering and Management, v. 12, n. 2, pp. 117-126, Jun, 2006.

[17] DAMINELI, B. L.; PILEGGI, R. G.; JOHN, V. M., "Influence of packing and dispersion of particles on the cement content of concretes", Revista IBRACON de Estruturas e Materiais, v. 10, n. 5, pp. 998-1024, Oct, 2017.

[18] HOPPE FILHO, J., SOUZA, D. J., MEDEIROS, M. H. F., et al., "Ataque de matrizes cimentícias por sulfato de sódio: adições minerais como agentes mitigadores", Cerâmica, v. 61, n. 358, pp. 168-177, Jun, 2015.

[19] CAMPOS, H.F., KLEIN, N.S., MARQUES FILHO, J., et al., "Low-cement high-strength concrete with partial replacement of Portland cement with stone powder and silica fume designed by particle packing optimization”, Journal of Cleaner Production, v. 261, e121228, Jul, 2020. 
[20] MEHTA, P. K.; MONTEIRO, P. J. M. Concreto: Microestrutura, Propriedades e Materiais,2 ed., São Paulo, IBRACON, 2014.

[21] COSTA, R. M., "Análise de propriedades mecânicas do concreto deteriorado pela ação de sulfato mediante utilização do upv", Tese de doutorado, UFMG, Belo Horizonte, MG, Brasil, 2004.

[22] QIN, S., ZOU, D., LIU, T., et al., "A chemo-transport-damage model for concrete under external sulfate attack”, Cement and Concrete Research, v. 132, e106048,Jun, 2020.

[23] CEFIS, N., COMI, C., "Chemo-mechanical modelling of the external sulfate attack in concrete", Cement and Concrete Research, v.93, pp. 57-70, Mar, 2017.

[24] TORRES, I. F. E ANDRADE, T., "Risk analysis of the delayed ettringite formation in pile caps foundation in the metropolitan region of Recife - PE - Brasil", Revista IBRACON de Estruturas e Materiais, v. 9, n. 3, pp. 357-394, Jun, 2016.

[25] LIU, P., CHEN, Y., WANG, W., et al., "Effect of physical and chemical sulfate attack on performance degradation of concrete under different conditions", Chemical Physics Letters, v. 745, e137254, Apr, 2020.

[26] GU, Y., MARTIN, R. P., METALSSI, O. O., et al. "Pore size analyses of cement paste exposed to external sulfate attack and delayed ettringite formation", Cement and Concrete Research, v. 123, e105766, Set, 2019.

[27] ASSOCIAÇÃO BRASILEIRA DE NORMAS TÉCNICAS (ABNT), NBR NM 248: Agregados - Determinação da composição granulométrica, Rio de Janeiro, 2003.

[28] ASSOCIAÇÃO BRASILEIRA DE NORMAS TÉCNICAS (ABNT), NBR NM 52: Agregado miúdo Determinação de massa específica e massa específica aparente, Rio de Janeiro, 2009.

[29] ASSOCIAÇÃO BRASILEIRA DE NORMAS TÉCNICAS (ABNT), NBR NM 53: agregado graúdo: determinação da massa específica, massa específica aparente e absorção de água, Rio de Janeiro, 2003.

[30] ASSOCIAÇÃO BRASILEIRA DE NORMAS TÉCNICAS (ABNT), NBR NM 16605: Cimento Portland e outros materiais em pó - Determinação da massa específica, Rio de Janeiro, 2017.

[31] FUNK, J. E; DINGER, D. R., "Predictive Process Control of Crowded Particulate Suspensions", In: Applied to Ceramic Manufacturing, Boston: Kluwer Academic Publishers, 1994.

[32] ARRUDA, R., MEIRA, G., BRAGA, F., et al., "Use of numerical method for optimization of granulometric curves in eco-efficient concrete", In: 9th International Conference On Concrete Under Severe Conditions - Environment and Loading - proceedings, pp. 1-10, Porto Alegre, Jun, 2019.

[33] SILVA, A. P.; SEGADÃES, A. M.; DEVEZAS, T. C., "Aplicação de métodos estatísticos na otimização da densidade de empacotamento de distribuições de pós de alumina", Cerâmica, v. 50, n. 316, pp. 345-354, Dec, 2004.

[34] HÜSKEN, G., BROUWERS, H. J. H., "A new mix design concept for earth-moist concrete: A theoretical and experimental study", Cement and Concrete Research., v. 38, n. 10, pp. 1246-1259, Oct, 2008.

[35] YU, R. D, ONNA,V. V., SPIESZ, P., et al.,"Development of Ultra-Lightweight Fibre Reinforced Concrete applying expanded waste glass", Journal of Cleaner Production, v. 112, pp. 690-701, Jan, 2016.

[36] ASSOCIAÇÃO BRASILEIRA DE NORMAS TÉCNICAS (ABNT), NBR NM 45: Agregados - Determinação da massa unitária e do volume de vazios, Rio de Janeiro, 2006.

[37] ASSOCIAÇÃO BRASILEIRA DE NORMAS TÉCNICAS (ABNT), NBR 5738: concreto: procedimento para moldagem e cura de corpos-de-prova, Rio de Janeiro, 2015.

[38] ASSOCIAÇÃO BRASILEIRA DE NORMAS TÉCNICAS (ABNT), NBR 13583: Cimento Portland Determinação da variação dimensional de barras de argamassa de cimento Portland expostas à solução de sulfato de sódio, Rio de Janeiro, 2014.

[39] TIAN, B.; COHEN, M. D., "Does gypsum formation during sulfate attack on concrete lead to expansion?", Cement and Concrete Research, v. 30, n. 1, pp. 117-123, Jan, 2000.

[40] KANTRO, D., "Influence of Water-Reducing Admixtures on Properties of Cement Paste- A Miniature Slump Test", Cement, Concrete and Aggregates, v. 2, n. 2, pp. 95, Jan, 1980.

[41] MONTE, R.; FIGUEIREDO, A. D., "Avaliação de métodos de ensaio de fluidez em pastas de cimento com aditivos superplastificantes", Boletim Técnico da Escola Politécnica da USP, São Paulo,SP, pp. 1-14, 2008. 
[42] ASSOCIAÇÃO BRASILEIRA DE NORMAS TÉCNICAS (ABNT), NBR NM 67: concreto: determinação da consistência pelo abatimento do tronco de cone, Rio de Janeiro, 1998.

[43] ASSOCIAÇÃO BRASILEIRA DE NORMAS TÉCNICAS (ABNT), NBR 5739: concreto: ensaio de compressão de corpos-de-prova cilíndricos, Rio de Janeiro, 2018.

[44] ASSOCIAÇÃO BRASILEIRA DE NORMAS TÉCNICAS (ABNT), NBR 9778: argamassa e concreto endurecidos: determinação da absorção de água, índice de vazios e massa específica, Rio de Janeiro, 2009.

[45] ASSOCIAÇÃO BRASILEIRA DE NORMAS TÉCNICAS (ABNT), NBR 5752: Materiais pozolânicos: Determinação do índice de desempenho com cimento Portland aos 28 dias, Método de ensaio, Rio de Janeiro, 2104.

[46] ASSOCIAÇÃO BRASILEIRA DE NORMAS TÉCNICAS (ABNT), NBR 12653: Materiais pozolânicos - Requisitos, Rio de Janeiro, 2014.

[47] LONDERO, C., "Dosagem de concreto ecológico com base em estudo de empacotamento de partículas", Dissertação de mestrado, UFPB, Curitiba, PR, Brasil, 2016.

[48] WASSERMANN, R.; KATZ, A.; BENTUR, A. "Minimum cement content requirements: A must or a myth?", Materials and Structures, v. 42, n. 7, pp. 973-982, Oct, 2009.

[49] SAMPAIO, Z. L. M., "Análise Do Comportamento Mecânico De Concretos Produzidos Com Incorporação De Cinza Do Bagaço Da Cana-De-Açúcar De Variedades Sp911049, Rb92579 E Sp816949”, Dissertação de mestrado, UFRN, Natal, RN, Brasil, 2013.

[50] FERNANDES, S. E., TASHIMA, M. M., MORAES, J. C. B., et al., "Cinza de bagaço de cana-deaçúcar (CBC) como adição mineral em concretos para verificação de sua durabilidade", Matéria, v. 20, n. 4, pp. 909-923, Dec, 2015.

[51] LINS, D. N., "Análise da resistência à compressão do cimento lc $^{3}$ e a influência das adições minerais em seu desempenho", Dissertação de mestrado, UNB, Brasília, DF, Brasil, 2017.

[52] VISCALDI, D. Z.; SILVA, B. V., "Análise do concreto submetido a ataque por sulfato de ferro em areas degradadas pela mineração do carvão", Trabalho de conclusão de curso, UNESC, Criciúma,SC, Brasil, 2014.

[53] BATISTA, D. G. "Investigação da deterioração de concretos de uhes por reações com os agregados", Dissertação de mestrado, UFG, Goiânia, GO, Brasil, 2013.

[54] PAULA, M. O., TINÔCO, I. F. F., RODRIGUES, C. S., et al., "Potencial da cinza do bagaço da canade-açúcar como material de substituição parcial de cimento Portland", Revista brasileira de engenharia agrícola ambiental, v.13, n.3, Jun, 2009.

[55] CORDEIRO, G. C., "Utilização de Cinzas Ultrafinas do Bagaço de Cana-de-Açúcar e da Casca de Arroz como Aditivos Minerais em Concreto", Tese de doutorado, COPPE/UFRJ, Rio de Janeiro, RJ, Brasil, 2006.

[56] MERCADO, L. H. B.; TOMMASELLI, M. A. G. "Absorção de concretos produzidos com red de concreto e cinza residual", In: $23^{\circ} \mathrm{CBECiMat}$ - Congresso Brasileiro de Engenharia e Ciência dos Materiais, Foz do Iguaçu, PR, Brasil, Nov, 2018.

[57] FILHO, L. C. P. S., "Durabilidade do concreto à ação dos sulfatos: Análise do efeito da permeação de água e da adição de microssílica", Dissertação de mestrado, UFRGS, Escola de Engenharia, Porto Alegre, RS, Brasil, 1994.

[58] ASSOCIAÇÃO BRASILEIRA DE NORMAS TÉCNICAS (ABNT), NBR 12655: Concreto de cimento Portland - Preparo, controle, recebimento e aceitação - Procedimento, Rio de Janeiro, 2015.

[59] GRAUPMANN, O., MARTINS, M. A., CONSUL, M., et al., "Análise da resistência à compressão de concretos com adição de cinza de aterro sanitário", Matéria, v. 24, n. 2, e12348, Jun, 2019.

[60] TANG, Z., LI, W., KE, G., et al., "Sulfate attack resistance of sustainable concrete incorporating various industrial solid wastes", Journal of Cleaner Production, v. 218, pp. 810-822, May, 2019.

\section{ORCID}

Alice Vitória Serafim Beserra

Leonardo de Souza Dias

Heberton Linhares Damaceno

Robson Arruda dos Santos https://orcid.org/0000-0002-2605-7916

https://orcid.org/0000-0001-5925-2171

https://orcid.org/0000-0003-3462-0075

https://orcid.org/0000-0001-5615-4365 